\title{
Muscoloskeletal manifestations in inflammatory bowel disease
}

\author{
Giovanni Fornaciari MD ${ }^{1}$, Carlo Salvarani $\mathrm{MD}^{2}$, Marina Beltrami MD ${ }^{1}$, PierLuigi Macchioni $\mathrm{MD}^{2}$, \\ Reinhold W Stockbrügger $\mathrm{MD} \mathrm{PhD}^{3}$, Maurice G Russel MD PhD ${ }^{3}$
}

G Fornaciari, C Salvarani, M Beltrami, P Macchioni, RW Stockbrügger, MG Russel. Musculoskeletal manifestations in inflammatory bowel disease. Can J Gastroenterol 2001;15(6):399-403. Muscoloskeletal manifestations are the most common extraintestinal complications of inflammatory bowel disease. Wide ranges in prevalence have been reported, depending on the criteria used to define spondylarthropathy. In 1991, the European Spondylarthropathy Study Group developed classification criteria that included previously neglected cases of undifferentiated spondylarthropathies, which had been ignored in most of the oldest epidemiological studies on inflammatory bowel disease. The spectrum of muscoloskeletal manifestations in inflammatory bowel disease patients includes all of the clinical features of spondylarthropathies: peripheral arthritis, inflammatory spinal pain, dactylitis, enthesitis (Achilles tendinitis and plantar fasciitis), buttock pain and anterior chest wall pain. Radiological evidence of sacroiliitis is common but not obligatory. The articular manifestations begin either concomitantly or subsequent to the bowel disease; however, the onset of spinal disease often precedes the diagnosis of inflammatory bowel disease. The prevalence of the different muscoloskeletal manifestations is similar in ulcerative colitis and Crohn's disease. Symptoms usually disappear after proctocolectomy. The pathogenetic mechanisms that produce the muscoloskeletal manifestations in inflammatory bowel disease are unclear. Several arguments favour an important role of the intestinal mucosa in the development of spondylarthropathy. The natural history is characterized by periods of flares and remission; therefore, the efficacy of treatment is difficult to establish. Most patients respond to rest, physical therapy and nonsteroidal anti-inflammatory drugs, but these drugs may activate bowel disease. Sulphasalazine may be recommended in some patients. There is no indication for the systemic use of steroids.

\section{Manifestations musculo-squelettiques et mal- adies inflammatoires de l'intestin}

RÉSUMÉ : Les manifestations musculo-squelettiques sont les complications extra-intestinales les plus fréquentes des maladies inflammatoires de l'intestin. La prévalence de la spondylarthropathie varie beaucoup selon les critères utilisés. En 1991, le groupe d'étude européen sur la spondylarthropathie a élaboré des critères de classification applicables aux cas autrefois négligés de spondylarthropathie indifférenciée et écartés de la plupart des premières études épidémiologiques sur les maladies inflammatoires de l'intestin. Les manifestations musculo-squelettiques des maladies inflammatoires de l'intestin comprennent tous les signes cliniques de la spondylarthropathie : arthrite périphérique, douleurs rachidiennes inflammatoires, dactylite, enthésite (tendinite achilléenne et fasciite plantaire), pygalgie et douleurs thoraciques antérieures. Les signes radiologiques de sacro-iléite sont fréquents mais non constants. Les manifestations articulaires apparaissent en même temps que la maladie de l'intestin ou plus tard; toutefois, l'affection médullaire commence souvent avant la pose du diagnostic de maladie inflammatoire de l'intestin. La prévalence des manifestations musculosquelettiques est la même pour la rectocolite hémorragique et la maladie de Crohn. Les symptômes disparaissent généralement après la proctocolectomie. On ne comprend pas très bien les mécanismes pathogéniques à l'origine des manifestations musculo-squelettiques des maladies inflammatoires de l'intestin. Plusieurs arguments permettent de croire que la muqueuse intestinale joue un rôle important dans l'apparition de la spondylarthropathie. L'évolution spontanée se caractérise par des périodes de poussée et de rémission; aussi l'efficacité du traitement est-elle difficile à déterminer. La plupart des patients réagissent bien au repos, à la physiothérapie et aux anti-inflammatoires non stéroïdiens, mais ceux-ci peuvent réveiller la maladie de l'intestin. La sulfasalazine peut convenir chez certains patients. Rien ne justifie le recours systématique aux stéroïdes.

Key Words: Extraintestinal manifestations; Inflammatory bowel disease; Spondylarthropathy

This mini-review was prepared from a presentation made at the World Congress of Gastroenterology, Vienna, Austria, September 6 to 11, 1998

${ }^{1}$ Unit of Gastroenterology, and ${ }^{2}$ Unit of Rheumatology, Arcispedale S Maria Nuova, Reggio Emilia, Italy; ${ }^{3}$ Department of Gastroenterology University Hospital Maastricht, The Netherlands

Correspondence and reprints: Dr Giovanni Fornaciari, Medicina III e Gastroenterologia, Arcispedale S Maria Nuova, viale Umberto I,

50, 42100, Reggio Emilia, Italy. Telephone +39-0522-296687, fax +39-0522-296604, e-mail fornaciari.giovanni@asmn.re.it

Received for publication November 28, 1999. Accepted November 30, 1999 
$\mathrm{T}_{\mathrm{p}}^{\mathrm{h}}$ he occurrence of extraintestinal manifestations in patients with inflammatory bowel disease (IBD) has been well recognized for many years; these manifestations are listed in Table 1. Muscoloskeletal disorders are the most common extraintestinal findings in both ulcerative colitis (UC) and Crohn's disease (CD). In 1930, Bargen (1) described, for the first time, arthritis complicating UC; in the following years, it was commonly believed that arthritis in patients with IBD was rheumatoid arthritis. After the introduction of the Rose-Waaler agglutination test, which helped to distinguish coincidental cases of rheumatoid arthritis, the term 'colitic arthritis' was proposed, and the first attempt was made to categorize the rheumatic complaints (2). Colitic arthritis was defined as recurrent, brief attacks of synovitis, usually asymmetrical and associated with exacerbation of intestinal symptoms, without progression to deformity. In 1976, Wright and Moll (3) proposed the inclusion of enteropathic arthropathy among the seronegative spondylarthropathies. UC and CD are not the only gastrointestinal disorders associated with rheumatological complications. As reported in Table 2, 'enteropathic arthropathy' is described in several other conditions as well.

\section{DEFINITIONS}

Arthritis associated with IBD belongs to the category of spondylarthropathies, which consists of several disorders (reactive arthritis, psoriatic arthritis, and ankylosing spondylitis in its juvenile and adult form). Two clinical patterns can occur: peripheral arthritis or axial disease. However, the clinical spectrum of spondylarthropathies is wider and includes other manifestations (Table 3). In 1991, the European Spondylarthropathy Study Group (ESSG) proposed new classification criteria (Table 4) that were easy to apply in clinical practice, with the aim of including previously neglected cases of undifferentiated disease (4). These criteria resulted in a sensitivity of $86 \%$ and a specificity of $87 \%$ in the diagnosis of spondylarthopathies (4). These criteria are superior to the New York modified criteria (Table 5) (5) for the diagnosis of ankylosing spondylitis; the New York modified criteria have a low sensitivity and are inadequate in describing the full clinical spectrum of spondylarthropathies (in particular, the undifferentiated forms).

In daily practice, a presumptive diagnosis of spondylarthropathies is usually supported by radiological evidence of sacroiliitis. However, the presence of sacroiliitis is a very frequent, but not necessarily early and obligate, manifestation of these conditions.

Some clinical characteristics are common to all forms of spondylarthropathies:

- Peripheral arthritis predominantly located in the lower limb (asymmetric)

- Tendency to sacroiliitis on $\mathrm{x}$-ray

- Absence of rheumatoid factor

- Absence of subcutaneous nodules and other extra-articular features of rheumatoid arthritis
TABLE 1

Extraintestinal manifestations of inflammatory bowel disease

\begin{tabular}{ll}
\hline Area & Manifestation \\
\hline Liver & Fatty change, primary sclerosing cholangitis, pericholangitis \\
Skin & $\begin{array}{c}\text { Erythema nodosum, pyoderma gangrenosum, aphthous } \\
\text { ulceration of the mouth, Sweet's syndrome }\end{array}$ \\
Eyes & $\begin{array}{l}\text { Episcleritis, anterior uveitis } \\
\text { Joints }\end{array}$ \\
Pystemic & Amyloipheral arthritis and sacroiliitis/ankylosing spondylitis \\
Other & $\begin{array}{l}\text { Thrombosis, nephrolithiasis, cholelithiasis, pericarditis, } \\
\text { lung diseases }\end{array}$ \\
\hline
\end{tabular}

TABLE 2

Classification of enteropathic arthritis

Infectious - Reactive arthritis (eg, Shigella, Salmonella, Yersinia, Campylobacter, Giardia lamblia)

Spondylarthropathy in inflammatory bowel disease

Miscellaneous - Arthritis observed in ileojejunal bypass, celiac disease, Whipple's disease, collagenous colitis

\section{TABLE 3}

\section{Muscoloskeletal manifestations of spondylarthropathies}

Peripheral arthritis - One or more swollen and tender joint(s); the synovitis is asymmetric and predominantly in lower limbs

Inflammatory spinal pain* - Symptoms of back pain in lumbar, dorsal or cervical regions associated with at least four of the following:

- Onset before age 45 years

- Insidious onset

- Improved by exercise

- Associated with morning stiffness

- Duration of at least three months

Dactylitis - Evidence of 'sausage digit' on examination

Peripheral enthesitis - Achilles tendinitis and/or plantar fasciitis

Buttock pain

Anterior chest wall pain

*Criteria of Calin et al (reference 43)

- Association with anterior uveitis

- Familial aggregation

- Association with human leukocyte antigen (HLA)-B27

\section{EPIDEMIOLOGY}

Differences in patient selection and in the definition of spondylarthropathy can explain, in part, the wide range in the prevalence of musculoskeletal disorders reported previously in IBD. Prevalence of peripheral arthritis has been 
TABLE 4

The European Spondylarthropathy Study Group criteria for spondylarthropathies*

Inflammatory spinal pain or synovitis (asymmetric, predominantly

in lower limbs) and any one of the following:

- Positive family history

- Psoriasis

- Inflammatory bowel disease

- Alternate buttock pain

- Enthesopathy

These criteria have a sensitivity of $77 \%$ and a specificity of $89 \%$

If sacroiliitis (radiological evidence) is added to the criteria, the sensitivity and specificity are $86 \%$ and $87 \%$, respectively. Data from reference 4

reported to be $11 \%$ to $20 \%(6,7)$. Ankylosing spondylitis has been diagnosed in 3\% to $6 \%$ of patients with IBD; however, radiological evidence of sacroiliitis has been reported much more frequently (14\% to $20 \%)$. In UC, a higher frequency of axial involvement (43\%) was reported by Scarpa et al (8). Of the patients studied by these authors, $25 \%$ satisfied the modified New York criteria for ankylosing spondylitis (5). In 14 (18\%) additional patients, inflammatory spinal pain was the only rheumatological manifestation. In an inception cohort of newly diagnosed IBD patients (9), 30.7\% had at least one muscoloskeletal manifestation, $18.5 \%$ satisfied the ESSG criteria for spondylarthropathy (4), and $2.6 \%$ satisfied only the criteria for ankylosing spondylitis (5; unpublished data). The results of these two studies show that the clinical spectrum of rheumatological manifestations is broader than that defined by spondylarthropathy criteria and that the prevalence of rheumatological findings in IBD may be higher than reported in the oldest studies.

There are no major differences between $\mathrm{UC}$ and $\mathrm{CD}$ in the occurrence of spondylarthropathy; it seems to be more prevalent in UC patients with chronic intermittent or continuous symptoms (10), and in ulcerative pancolitis (7). The presence of peripheral arthritis is frequently associated with other extraintestinal manifestations, such as erythema nodosum and anterior uveitis $(11,12)$. There is a strong association between peripheral arthritis and colonic localization of CD (12,13). A recent prospective study reported that peripheral arthritis occurred more frequently in patients with CD than in patients with UC (20.2\% compared with $11.0 \%$, respectively) (12).

\section{CLINICAL COURSE}

Although in most cases intestinal symptoms coincide with or precede the articular manifestations, spinal involvement can precede the diagnosis of IBD. The onset of peripheral arthritis is often abrupt, with spontaneous pain, erythema, hyperemia and effusion. The joints of the lower limb are most commonly affected, but elbows, metacarpophalangeal joints and shoulders can be involved as well (14). The peripheral arthritis is frequently self-limiting and nondeforming, but may become erosive and chronic in a limited
TABLE 5

Modified New York criteria for the diagnosis of ankylosing spondylitis

Unilateral sacroiliitis grade 3 or 4 , or bilateral sacroiliitis grade 2 to 4 together with at least one of the following:

- Low back pain of at least three months' duration improved by exercise and not relieved by rest

- Limited motion of lumbar spine in sagittal and frontal planes

- Decreased chest expansion relative to normal values for age and sex

Data from reference 5

TABLE 6

Classification of peripheral arthropathy

Type 1 (pauciarticular)

- Less than five joints

- Acute, self-limiting attacks (less than 10 weeks)

- Often coincides with relapses of inflammatory bowel disease

- Strongly associated with other extraintestinal manifestations

Type 2 (polyarticular)

- Five or more joints

- Symptoms usually persist for months to years

- Course independent of inflammatory bowel disease

- Associated only with uveitis

Data from reference 16

number of patients (15). A new classification of peripheral arthritis has been proposed according to presentation, joint involvement and course of the disease (Table 6) (16). Clinically, type 1 arthropathy was similar to reactive (infectious) arthritis, with self-limiting attacks of oligoarthritis, while type 2 arthropathy was reported to run a more severe course independent of IBD activity. This classification is helpful to divide these syndromes into subgroups, but its usefulness has to be confirmed in clinical practice.

Axial involvement in IBD patients includes radiological evidence of sacroiliitis, ankylosing spondylitis and undifferentiated spondylarthropathies. Usually, there is no association between the severity of bowel disease and the course of spinal involvement. The association with other extraintestinal manifestations is less evident than in peripheral arthritis. Symptoms at onset are similar to idiopathic ankylosing spondylitis: the patient complains of low back pain with morning stiffness, and alternating buttock or chest pain. The back pain is usually exacerbated by prolonged sitting or standing, or after night rest.

Usually, arthritic symptoms disappear after proctocolectomy (13); however, joint symptoms may reappear after restorative proctocolectomy $(17,18)$. The relationship between the inflammation of reconstructed ileal pouch (pouchitis) and the occurrence of arthropathy is unclear. A recent well planned prospective case-control study showed no correlation between occurrence of pouchitis and occurrence of arthropathy in UC patients (18). 


\section{DIAGNOSIS}

The diagnosis of arthropathy in IBD patients is mainly based on history and clinical evaluation; the importance of clinical evaluation performed by a rheumatologist has been stressed previously (8). For the detection of sacroiliitis, conventional radiography, bone scanning, computed tomography and magnetic resonance imaging are used $(14,19)$. In clinical practice, the diagnosis of sacroiliitis is accurately assessed by a simple pelvic x-ray (20). Sacroiliac joint involvement is graded according to the New York criteria (21).

The diagnosis of peripheral arthritis is clinical. The evidence of joint swelling or effusion is diagnostic. Radiographs of the involved joints usually show no abnormalities. Erosive disease of the hip, as well as metacarpophalangeal and metatarsophalangeal joints, has been reported $(22,23)$. Synovial fluid analysis and histology of synovial tissue usually show a nonspecific inflammation (11).

No association with HLA-B27 is present in peripheral arthritis. In ankylosing spondylitis, the association with HLA-B27 is less strong (50\% to $75 \%$ ) than in the idiopathic form (90\% to $95 \%)(8,24,25)$.

\section{PATHOGENESIS}

The pathogenesis of peripheral arthritis is unclear; the role of bacterial antigens, such as those in reactive arthritis and arthritis following intestinal bypass surgery, seems to be important (26). Several studies have focused on an important 'gut-synovium axis' (11,26-28). Furthermore, a crossreactivity between gut bacteria and cartilage in patients with CD has been demonstrated (29).

Genetic predisposition may not be as important in patients with IBD who have spondylitis as in patients without IBD who have spondylitis, because these latter patients have much stronger association with HLA-B27 $(8,24,25)$. The altered gut permeability could be a key factor in the development of spondylarthropathy.

The relationship between seronegative spondylarthropathy and IBD is very interesting. A non-negligible number of patients may be affected by rheumatological symptoms many years before the diagnosis of IBD (16). Recent studies have suggested that $6 \%$ of patients with spondylarthropathy will develop IBD. However, patients with negative gut histology at the time of arthritis will never develop IBD $(30,31)$. In one study, colonoscopy was performed in 118 patients with various inflammatory and noninflammatory joint conditions. Endoscopic lesions were reported in 44\% of patients with spondylarthropathy (32), and 26\% of patients had histology consistent with CD. According to these data, it can be hypothesized that gut and joint inflammation are coincidental, and that they can be triggered by the same agent. The sharing of certain peptides by colonic epithelium, ciliary processes of the eye and chondrocytes of the joints is a possible pathogenic mechanism (33) that could also explain the association of arthritis with other extraintestinal manifestations.
The inflammatory lesions in pouchitis are different from those present in UC, because pouchitis usually responds to antibiotic treatment (34). Studies exploring the relationship between arthropathy and pouchitis may be very useful in clarifying the pathogenic mechanisms of joint involvement in pouchitis.

\section{TREATMENT}

The natural history of muscoloskeletal manifestations in IBD is characterized by alternating periods of flares and spontaneous remission; therefore, the usefulness of treatment is difficult to assess. The aims of therapy are to reduce inflammation, and to prevent disability or deformity.

In general, patients are managed by simple means: rest, physical therapy and intra-articular steroid injection. In patients with axial involvement, intensive physiotherapy is useful to prevent spinal joint fusion and to maintain optimal motility $(14,35)$. Nonsteroidal anti-inflammatory drugs (NSAIDs) are usually prescribed to control peripheral arthritis, back pain and stiffness. Caution is necessary because these drugs may activate quiescent $\operatorname{IBD}(36,37)$. In patients with joint symptoms preceding IBD onset, it has been claimed that there is a causal relationship of IBD onset with NSAID therapy $(11,38)$.

In axial involvement, sulphasalazine (SASP) has been recommended as the drug of choice, and a shift from mesalazine to SASP has been suggested if the colon is intact (34). Several placebo controlled trials have reported a beneficial effect of SASP $(39,40)$. The efficacy of SASP appears to be related to sulphapyridine, although this question has not been completely answered (41). Data about the long term results of SASP treatment are more scarce; the drug seems to achieve better results on peripheral arthritis than on axial involvement (40).

Other slow acting agents, such as azathioprine and 6-mercaptopurine, have not been studied as closely (42). The occurrence of arthritis is not an indication for steroid therapy; however, if the previously reported treatments are scarcely effective, a short course of steroids is mandatory. The spontaneous remission of joint symptoms, particularly in peripheral arthritis, must always be considered for the management of patients with rheumatic symptoms secondary to IBD.

\section{CONCLUSIONS}

Inflammatory bowel disease is a heterogeneous disorder in which patients manifest a spectrum of symptoms related to intestinal and extraintestinal manifestations. Muscoloskeletal manifestations are the most common IBD extraintestinal manifestations and may be present in 30\% of patients. Their spectrum is wider than that defined by the spondylarthropathy criteria. In most cases, intestinal symptoms coincide with or precede articular manifestations. The gut-joint axis appears to be an important pathogenic factor. Rest, physical therapy, intra-articular steroid injection and NSAIDs are usually prescribed to control peripheral arthritis, back pain and stiffness. SASP seems to be more effective for peripheral arthritis than for axial disease. 


\section{REFERENCES}

1. Bargen JA. Complications and sequelae of chronic ulcerative colitis. Ann Intern Med 1930;3:335-9.

2. Wright W, Watkinson G. The arthritis of ulcerative colitis. Medicine 1959;38:243-59.

3. Wright W, Moll JMH, eds. Seronegative Polyarthritis. Amsterdam: North Holland Publishing, 1976.

4. Dougados M, van der Linden S, Juhlin R, et al. The European Spondylarthropathy Study Group preliminary criteria for the classification of spondylarthropathy. Arthritis Rheum 1991;34:1218-27.

5. van der Linden S, Valkenburg HA, Cats A. Evaluation of diagnostic criteria for ankylosing spondylitis: a proposal for modification of the New York criteria. Arthritis Rheum 1984;27:361-8.

6. Moll JMH. Inflammatory bowel disease. Clin Rheum Dis 1985;11:87-111.

7. Bardazzi G, Mannoni A, d'Albasio G, et al. Spondyloarthritis in patients with ulcerative colitis. Ital J Gastroenterol Hepatol 1997;29:520-4.

8. Scarpa R, Del Puente A, D'Arienzo A, et al. The arthritis of ulcerative colitis: clinical and genetic aspects. J Rheumatol 1992;19:373-7.

9. Shivananda S, Lennard Jones J, Logan R, et al. Incidence of inflammatory bowel disease across Europe: is there a difference between North and South? Results of the European Collaborative Study on inflammatory bowel disease (EC-IBD). Gut 1996;39:690-7.

10. Isdale A, Wright W. Seronegative arthritis and the bowel. Baillieres Clin Rheumatol 1989;3:285-301.

11. de Vos M, de Keyser F, Mielants H, Cuvelier C, Veys E. Review article: bone and joint diseases in inflammatory bowel disease. Aliment Pharmacol Ther 1998;12:397-404.

12. Tavarela Veloso F, Carvalho J, Magro F. Immune-related systemic manifestations of inflammatory bowel disease: a prospective study of 792 patients. J Clin Gastroenterol 1996;23:29-34.

13. Monsén U, Sorstad J, Hellers G, Johansson C. Extracolonic diagnoses in ulcerative colitis: an epidemiological study. Am J Gastroenterol 1990;85:711-6.

14. Meuwissen SGM, Crusius JBA, Salvador Pena A, Dekker-Saeys AJ, Dijkmans BAC. Spondyloarthropathy and idiopathic inflammatory bowel diseases. Inflamm Bowel Dis 1997;3:25-37 .

15. Mielants H, Vyes EM, Goethals K, et al. Destructive lesions of small joints in seronegative spondyloarthropathies: relation to gut inflammation. Clin Exp Rheumatol 1990;8:23-7.

16. Orchard TR, Wordsworth BP, Jewell DP. Peripheral arthropathies in inflammatory bowel disease: their articular distribution and natural history. Gut 1998;42:387-91.

17. Andreyev HJN, Kamm MA, Forbes A, Nicholls RJ. Joint symptoms after restorative proctocolectomy in ulcerative colitis and familial polyposis coli. J Clin Gastroenterol 1996;23:35-9.

18. Thomas PD, Keat AC, Forbes A, Ciclitira PJ, Nicholls RJ. Extraintestinal manifestations of ulcerative colitis following restorative proctocolectomy. Eur J Gastroenterol Hepatol 1999;11:1001-5.

19. Battafarano DF, West SG, Rak KM, Fortenbery EJ, Chantelois AE. Comparison of bone scan, computed tomography, and magnetic resonance imaging in the diagnosis of active sacroiliitis. Semin Arthritis Rheum 1993;23:161-76.

20. Mau W, Zeidler H, Mau R, et al. Clinical features and prognosis of patients with possible ankylosing spondylitis: results of a 10-year follow up. J Rheumatol 1988;15:1109-14.

21. Bennet PH, Burch TA. Symposium of population studies in the rheumatic diseases: new diagnostic criteria. Bull Rheum Dis 1967;17:453-8.

22. Protzner U, Duchmann R, Hohler T, et al. Enteropathic spondylarthropathy in chronic inflammatory bowel disease: prevalence pattern of manifestations and HLA-association. Ed Klin 1996;91:330-5.

23. Beauvais C, Lequintrec JL, Prier A, Flipo RM, Kahn MF, Kaplan G. Destructive arthritis of the hip in Crohn's disease. Presse Med 1995;24:1555-8.

24. Fomberstein B, Yerra N, Pitchumoni CS. Rheumatological complications of GI disorders. Am J Gastroenterol 1996;91:1090-103.

25. Huaaux JP, Falssi R, De Bruyere M. HLA B27 in regional enteritis with and without ankylosing spondylitis and sacroiliitis. J Rheumatol 1997;4(Suppl 3):60-3.

26. Cuvelier CA, Quatacher J, Mielants H, et al. M-cells are damaged and increased in number in inflamed human ileal mucosa. Histopathology 1994;24:417-26.

27. Salmi M, Andrew DP, Butcher EC, et al. Dual binding capacity of mucosal immunoblasts to mucosal and synovial endothelium in human dissection of the molecular mechanism. J Exp Med 1995;181:137-49.

28. Elewaut D, de Vos M, de Keyser F, et al. Distinctive cell activation markers in colon from patients with Crohn's disease and ulcerative colitis. Gastroenterology 1997;112:A718. (Abst)

29. Van der Broek MF, van de Putte LBA, van den Berg WB. Crohn's disease associated with arthritis. A possible role for cross-reactivity between gut bacteria and cartilage in the pathogenesis of arthritis. Arthritis Rheum 1988;31:1077-9.

30. Mielants H, Veys E, de Vos M, et al. The evolution of spondylarthropathy in relation to gut histology. I. Clinical aspects. J Rheumatol 1995;22:2266-72.

31. Mielants H, Veys E, Cuvelier C, et al. The evolution of spondylarthropathy in relation to gut histology. II. Histological aspects. J Rheumatol 1995;22:2279-84.

32. Leirisalo Repo M, Turunen U, Stenman S, Helenius P, Seppala K. High frequency of silent inflammatory bowel disease in spondylarthropathy. Arthritis Rheum 1994;1:23-31.

33. Bhagat S, Das KM. A shared and unique peptide in the human colon, eye and joint detected by monoclonal antibody. Gastroenterology 1994;107:103-8.

34. Brynskov J, Binder V. Arthritis and the gut. Eur J Gastroenterol Hepatol 1999; 11:997-9.

35. Levine JB, Lukawskitrubish D. Extraintestinal considerations in inflammatory bowel disease. Gastroenterol Clin North Am 1995;24:633-46.

36. Kaufmann HL, Fisher AH, Carroll M, Becker JM. Colonic ulceration associated with nonsteroidal anti-inflammatory drugs. Dis Colon Rectum 1996;39:705-10.

37. Kaufmann HJ, Taubin HL. NSAIDs activate quiescent inflammatory bowel disease. Ann Intern Med 1987;107:513-6.

38. Rampton DS, Mc Neil NI, Sarner M. Analgesic ingestion and other factors preceding relapse in ulcerative colitis. Gut 1983;24:187-9.

39. Ferraz MB, Tugwell P, Goldsmith CH, Atra E. Meta-analysis of sulphasalazine in ankylosing spondylitis. J Rheumatol 1990;17:1482-6.

40. Dougados M, van der Linden S, Leirisalo-Repo M, et al. Sulphasalazine in the treatment of spondylarthropathy: randomized, multicenter, doubleblind, placebo controlled study. Arthritis Rheum 1995;38:618-27.

41. Taggart A, Gardiner P, Mc Evoy F, Hopkins R, Bird H. Which is the active moiety of sulphasalazine in ankylosing spondylitis? A randomized, controlled study. Arthritis Rheum 1996;39:1400-5.

42. Creemers MCW, Van Riel PLCM, Franssen MJAM, et al. Second-line treatment in sero-negative spondylarthropathies. Semin Arthritis Rheum 1994;24:71-81.

43. Calin A, Porta J, Fries JF, Schurman DJ. Clinical history as a screening test for ankylosing spondylitis. JAMA 1977;237:2613-4. 


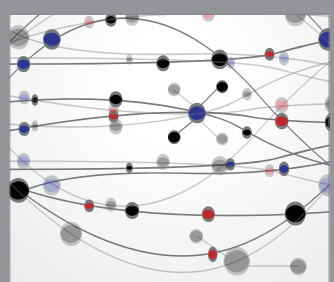

The Scientific World Journal
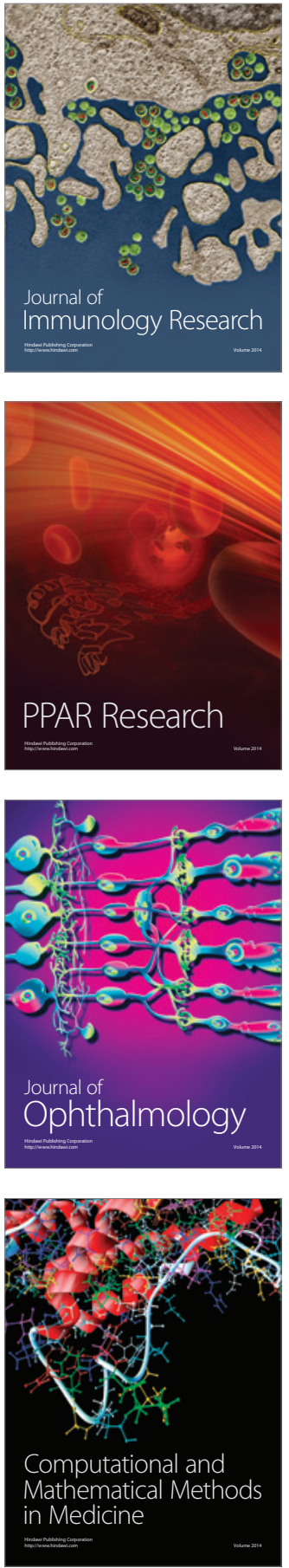

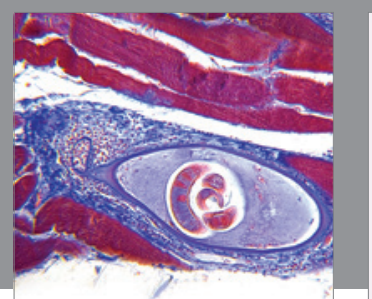

Gastroenterology Research and Practice

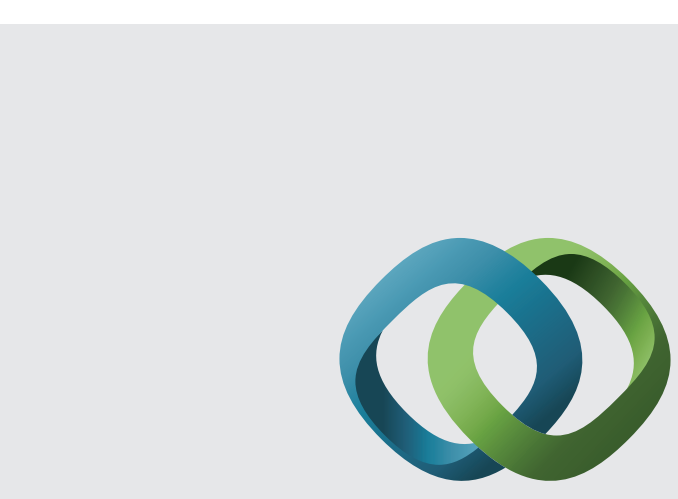

\section{Hindawi}

Submit your manuscripts at

http://www.hindawi.com
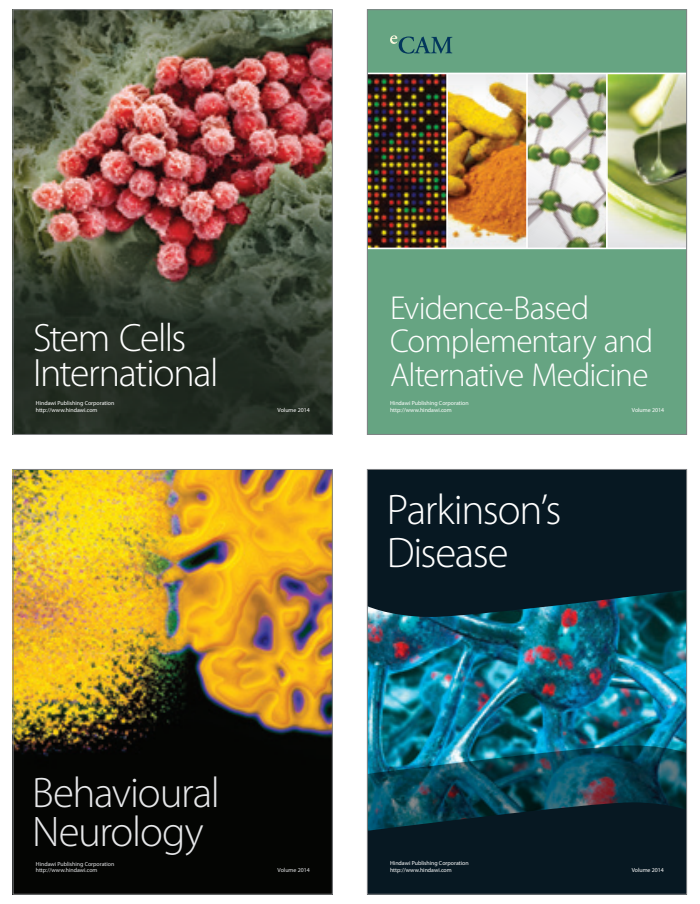
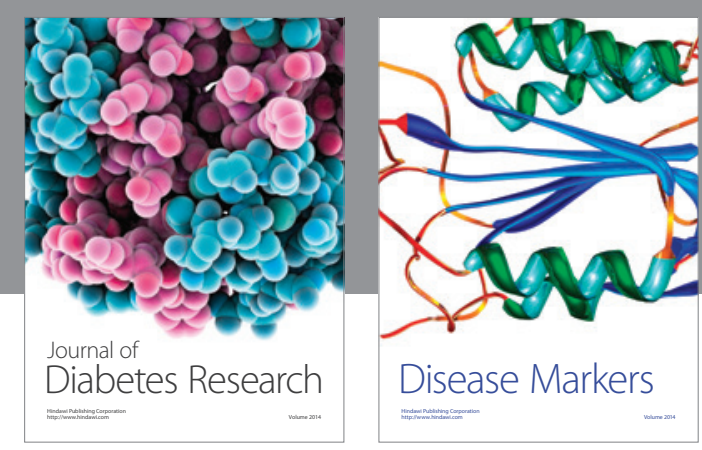

Disease Markers
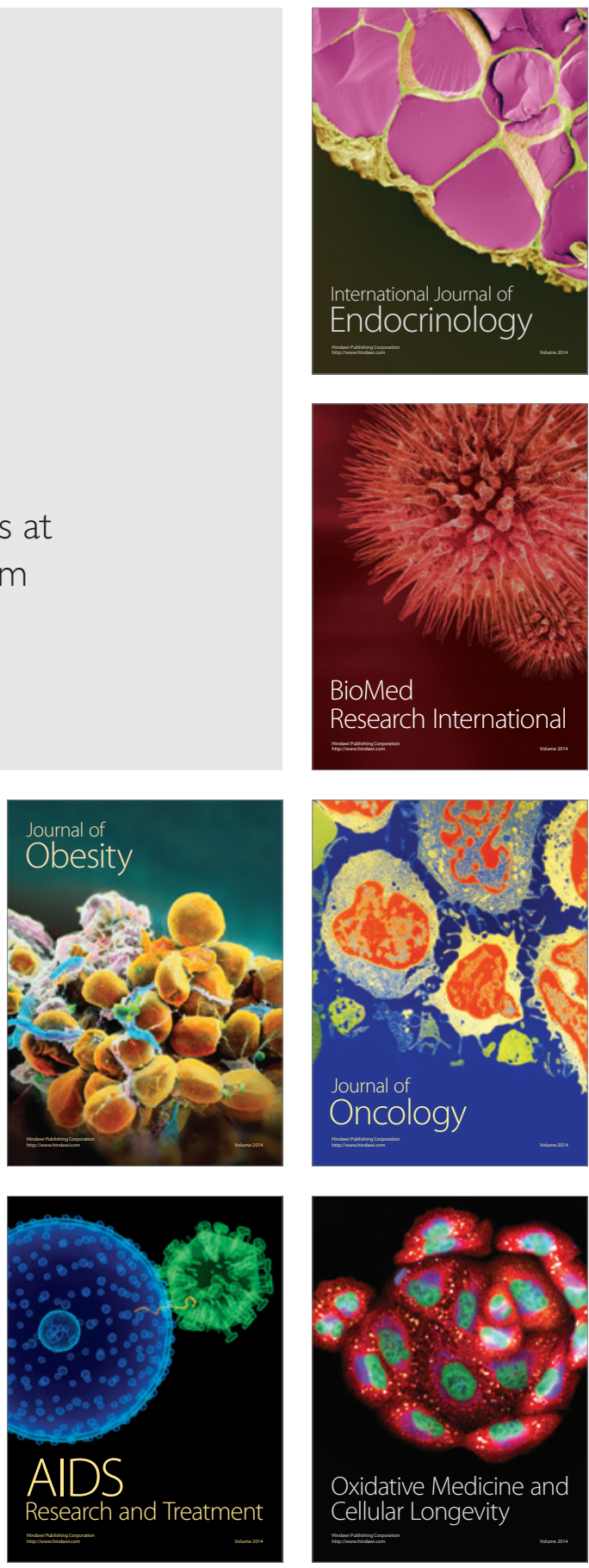